ARTIGO

Recebido em:

29/12/2015

Aceito em:

26/02/2016

\title{
Redes sociais virtuais na sociedade da informação e do conhecimento: economia, poder e competência informacional
}

\author{
Virtual social networks in the information society and knowledge: \\ economy, power and informational competence
}

Edna ANGELO
$\begin{aligned} & \text { Bibliotecária do Conselho Regional de Medicina de } \\ & \text { ednasangelo@yahoo.com.br }\end{aligned}$

\section{Resumo}

Este artigo tem como objetivo fazer um apanhado teórico a respeito das redes sociais virtuais a fim de contextualizar sua conjuntura na sociedade contemporânea. Conclui-se que por meio das redes sociais virtuais, certamente o usuário não será capaz de dominar o universo informacional tornando-se autônomo para designar habilidades ligadas ao uso da informação e criando soluções para seus problemas para se denominar competente informacional. No entanto, pode se apresentar como uma porta de entrada para interagir com a tecnologia e procurar novas fontes de informação, rumo à aquisição de novos conhecimentos. 0 mundo "business", por sua vez (empresas e marcas), caminha para encarála de forma cada vez mais séria e profissional. É aí que está à comunicação da nova "era do conhecimento": será no mundo virtual que os consumidores e marcas dialogarão.

Palavras-chaves: Redes sociais virtuais. Economia da informação. Competência informacional.

\begin{abstract}
This article aims to make a theoretical overview about social networks in order to contextualize their situation in contemporary society. In conclusion, through social networks, certainly you will not be able to master informational universe becoming autonomous to designate skills related to the use of information and creating solutions for their problems to be called competent informational. However, it can present itself as a gateway to interact with technology and seek new sources of information, towards the acquisition of new knowledge. The world "business" in turn (companies and brands), walks to face her increasingly serious and professional manner. That's where the communication of the new "knowledge age": is the virtual world that consumers and brands will dialogue. Keywords: Virtual Social Networks. Information economy. Information literacy.
\end{abstract}

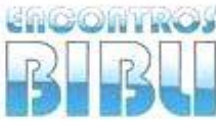

v. 21, n. 46,2016 p. $71-80$

ISSN 1518-2924
Esta obra está licenciada sob uma Licença Creative Commons. 


\section{REDES SOCIAIS VIRTUAIS}

Um dos grandes fenômenos resultantes do uso intenso da internet é a ampliação do número de redes sociais, motivada pela velocidade da comunicação, pelo grande alcance dos espaços geográficos e pela disseminação das tecnologias da informação e comunicação.

Redes sociais são, antes de qualquer coisa, relações entre pessoas, estejam elas interagindo em causa própria, em defesa de outrem, ou em nome de uma organização. Tendem a ser abertas à participação (por afinidades) e não deterministas nos seus fins (que podem ir sendo modificados ao sabor dos acontecimentos, porém mantendo a motivação inicial que gerou a rede) (AGUIAR, 2006).

São redes de comunicação que envolvem a linguagem simbólica, os limites culturais e as relações de poder - definição que, conforme Fritjot Capra (2007), resume de forma preciosa o alcance das redes como instrumento político social de combate à pobreza, como veículo de expressão e manifestação de valores, ideias, pensamentos, atitudes, posicionamentos políticos e manifestações culturais, como dispositivos de entretenimento e lazer e como agentes de trabalho.

A dinâmica das comunidades conectando-se através de computadores a transformaram em instrumentos de alcance global com um potencial significativo de influência na sociedade, na cultura, na economia, na política e na educação, como nos sugere o parágrafo a seguir:

0 conceito de rede sempre esteve presente enquanto elemento estruturante das relações cognitivas e sociais. Contudo, na década de 90 assiste-se à hiperbolização do conceito de rede com a expansão das redes e serviços telemáticos. [...] Deste modo será útil compreender que existe um processo dialético entre comunicação e comunidade estruturado pelas redes que se estabelecem entre os sujeitos (SILVA, 1999).

De acordo com Michel Serres (2004) as "novas" tecnologias são muito mais antigas do que imaginamos. Na realidade, existem dois tipos de tecnologia: as de natureza técnica que vão do quebra-nozes à bomba-atômica e as de natureza informacional. A palavra tecnologia, segundo o filósofo, nos dá a impressão de que uma evoluiu da outra, o que é falso.

Ainda citando Michel Serres (2004):

0 historiador André Leroi-Gourhan assim descrevia o processo de hominização: o homem quando se pôs de pé para se deslocar, liberou os seus membros anteriores da função de transporte que até então desempenhavam. A mão pode então desenvolver a capacidade de preensão e o ser humano se tornou um homo faber. Ao retirar da mão esta faculdade de preensão a boca - que até então preenchia tal função - a perdeu e pôde, então, falar...Ora, se buscarmos então neste processo, o ganho da palavra e a perda da função de transporte, não há dúvida de que o ganho transcende largamente, a perda. Será isso o que novamente ocorre?

Nesta evolução, é o sujeito humano - ele próprio, em sua dimensão cognitiva, que se modifica. Mas ele sempre se transformou na medida em que as tecnologias dúcteis evoluíram (SERRES, 2004).

Refletindo sobre as afirmações acima, podemos imaginar que a evolução das tecnologias informacionais como as redes virtuais, assim como outras do passado, como, por exemplo a escrita, modificarão intensamente as relações humanas. 
A força das redes sociais intermediadas pelas TIC's reside no fato de que ela combina três características importantes: a liberdade, a capacidade e o alcance do indivíduo, assim, conforme Michel Serres (2004), a internet ainda é um espaço de não-direito onde muitas transformações têm lugar. Esta combinação faz com que saberes ocultos e relevantes para a humanidade, possam circular e ser de alguma forma capturados, entendidos e potencializados por outros autores de outros saberes.

No entanto, por ser um espaço de não-direito, as redes sociais servem a propósitos diversos, nem sempre enriquecedores para a vida do cidadão. Se por um lado elas atendem às demandas sociais de conhecimento elas também atendem a interesses muitas vezes danosos às próprias comunidades que as utilizam.

\section{CENÁRIO ECONÔMICO POLÍTICO DA INFORMAÇÃO NA WEB}

Muito se tem discutido a respeito dos impactos causados pelo uso das tecnologias da informação e comunicação, que a partir dos anos 90 romperam paradigmas e estabeleceram novos tipos de relações sociais, interferindo de forma significativa nas estruturas político-econômicas do mundo.

Tipicamente produtos de um mundo economicamente globalizado, as tecnologias da informação e comunicação possuem características peculiares que têm provocado a atenção das diversas áreas de conhecimento uma vez que ainda não são totalmente conhecidas, as conseqüências do seu uso na sociedade contemporânea. Os autores: Helena M.M. Lastres, José E. Cassiolato e Ana Arroio (2005) chamam atenção para o desequilíbrio provocado pela difusão destas tecnologias:

A difusão das TICS permitiu a interconexão, em tempo real, das regiões distintas e geograficamente distantes. A comunicação e a troca de informação passaram a ser feitas em quantidade e velocidade nunca antes experimentadas. Entretanto, ao mesmo tempo em que se ampliou o processo de globalização, novas formas de polarização e exclusão foram criadas. Elas estão associadas, por um lado, à capacidade desigual de desenvolver, produzir e usar novas tecnologias, bens e serviços; por outro lado, às oportunidades também desiguais, para adquirir e renovar as bases de conhecimento e as habilidades necessárias para utilizalas (LASTRES; CASSIOLATO, 2005, p. 24).

Certamente, cresceram neste contexto, as estruturas capitalistas mais ricas, que expandiram seus domínios ganhando adeptos em novos mercados e ganhando acima de tudo o poder de encantar grandes massas de consumidores utilizando a precisão da informação, a velocidade da comunicação e o alcance das mídias.

Latres, Cassiolato e Ana Arroio (2005) questionam: existe uma tendência à globalização ou à exclusão? Eles chamam atenção ao processo de divisão, que contribui para aumentar as desigualdades atuais entre países industrializados e não industrializados. Esta divisão caracteriza-se pela concentração em poucas organizações e regiões do mundo das atividades de desenvolvimento, produção e comercialização de bens e serviços digitais.

No entanto, é interessante observar que o conjunto das tecnologias da informação e comunicação, mesmo dentro de um contexto desequilibrado de oportunidades, permitiu a criação de uma grande diversidade de redes sociais, apoiadas no uso da internet, que nem sempre estão a serviço dos interesses daqueles que fornecem as tecnologias. Se por um, lado a globalização da economia contribui para a exclusão de grandes contingentes populacionais, por outro ela pode também criar condições favoráveis de inclusão para diferentes tipos de comunidade. 
Embora muitas discussões girem em torno dos males do processo de globalização, sobre as limitações do acesso às tecnologias da informação, sobre a falta de conhecimento para a utilização deste instrumento de forma a desenvolver e inserir o cidadão na sociedade, ainda assim, é inquestionável o poder das redes digitais. Poder de mobilização, de influência, de interação, de pertencimento, de acolhimento e de desenvolvimento. Um número imenso de "novos coletivos" formase no ambiente da WEB, como contra ponto a uma estrutura globalizada rígida, opressora e desigual. No entanto, não se trata de movimentos contra a globalização. Trata-se de uma globalização fluida cujos movimentos em sua grande maioria reivindicam uma outra forma de estar no mundo.

Manuell Castells (2006) chama de Mass Self Comunication (intercomunicação individual) ao movimento constituído por uma nova forma de comunicação em massa que é produzida, recebida e experimentada individualmente e que confere à sociedade maior capacidade de controle, intervenção e organização política. Em sua entrevista ao Le Monde Diplomatique, o sociólogo aponta para a crise de legitimidade política em escala mundial, pela prática do escândalo, a midiatização exacerbada da cena pública e a falta de confiança dos cidadãos no sistema. Essa desconfiança pode ser ilustrada por uma pesquisa feita pelos serviços da Organização das Nações Unidas (ONU) segundo a qual dois terços dos habitantes do planeta afirmam não se sentir representados pelos seus governantes. Esta população que desconfia, também crê que pode agir no mundo através da sua força de vontade e utilizando seus próprios meios.

Sandra Braman (2005), no relatório Information Technology, National Identity, \& Social Cohesion - A Report of The Project on Technology Futures and Global Power, Wealth, and Conflict, descreve as 5 características das tecnologias da informação atuais que experimentadas pelo uso individual afetam o potencial político destas tecnologias:

1. capacidade;

2. o uso do software para facilitar o desenvolvimento de tipos particulares de relações sociais;

3. a programabilidade e adaptabilidade destas tecnologias;

4. a habilidade de indivíduos de produzir conteúdo para distribuição em massa; e

5. a prática comum de combinar vários tipos de mídia para ativar um propósito político ou social.

Juntando as peças do cenário atual temos: na economia, um novo padrão de acumulação desmaterializado, financeirizado, com a mercantilização e controle dos conhecimentos dividindo e excluindo populações; na política, povos que não se vêm representados por seus governos, pela falta absoluta de governança e governabilidade; na sociedade, a necessidade do cidadão de se defender diante das dificuldades geradas pelas novas condições políticas e econômicas atuais.

Esta combinação reforça a ideia de que as redes sociais potencializadas com a capacidade individual das TIC's conferem ao cidadão o poder de ver e de ser visto, de acolher e ser acolhido, e de atuar no mundo mesmo de forma marginal às instituições formais que ele não reconhece e por quem não é reconhecido.

A batalha entre a cultura globalizada e mercantil e a cultura local como expressão da "alma" do cidadão, não deve terminar na escolha de uma ou de outra. As redes sociais são um instrumento importante que pode ser utilizado para integrar regiões de competências complementares, disseminar e resgatar potencialidades difusas de comunidades, promover o desenvolvimento de bolsões de pobreza, pela possibilidade de poder estabelecer um canal entre o global e o local, como uma ponte que serve para encurtar um longo e árduo caminho. 
Contudo, somos parte integrante desta globalização, e talvez ainda não tenhamos o distanciamento histórico necessário para alcançarmos conclusões mais concretas dos efeitos das redes sociais.

\section{COMPETÊNCIA INFORMACIONAL}

A tecnologia da Informação possibilita o acesso à informação a várias pessoas em tempo simultâneo. No entanto, é preciso estabelecer a compreensão do conteúdo disponibilizado, saber utilizar esses recursos e aplicativos da tecnologia de forma a gerir a conexão à capacitação do usuário (MELARY, 2005). A dinâmica social global pode ser pontuada como:

1. Sociedades em rede,

2. Info-estruturas de conexão,

3. Novas formas de pensar e de se relacionar com a realidade,

4. Economia informacional,

5. Cultura de informação (BELUZZO, 2005).

Cenário esse viabilizado pelas novas formas de acesso à informação; inclusão e uso intensivo de TICs; escassez de tempo e sobrecarga de informação exigindo sujeitos mais autônomos e participativos (FERREIRA, 2005). Conforme relata Drucker (1993, p.165 apud BARRETO, 2005) se nas sociedades anteriores, a pessoa instruída era um ornamento, na sociedade do conhecimento, a pessoa instruída é o emblema, o símbolo, a porta bandeira [...] ela define a capacidade de desempenho da sociedade, mas também incorpora seus valores, crenças e compromissos.

0 conhecimento deixou de ser visto como mera aquisição de informação para ser reconhecido na dimensão da construção e valorização do sujeito (BARRETO, 2005). Essa exigência vem demandando novos contextos para paramentar de forma mais clara o vasto conteúdo informacional disponibilizado, principalmente na web. Deve-se saber retirar palavras-chaves e informações eixos para entender o contexto geral e depois aprimorar na leitura do texto na íntegra (MELARY, 2005).

Essas necessidades levaram a ideia de capacitar o indivíduo a ter o "domínio sobre o universo informacional" referente à capacitação dos indivíduos frente a essa nova realidade. 0 desenvolvimento da competência informacional é um desses ensejos revelando a urgência em preparar o ser humano para compreender:

1. como definir suas necessidades informacionais,

2. como buscar e acessar efetivamente a informação necessária,

3. como avaliá-la (pertinente ou não, relevante ou não),

4. como organizá-la,

5. como transformá-la em conhecimento,

6. como aprender a aprender,

7. como aprender continuamente (DUDZIAK, 2002).

O estudo sobre competência informacional iniciou-se nos Estados Unidos em 1974. A expressão utilizada no trabalho (Information Literacy) ganhou diversas traduções no Brasil, como: alfabetização informacional, letramento, literacia, fluência informacional, competência em informação.

Três concepções de competência informacional se destacam: a concepção da informação; a concepção cognitiva e a concepção da inteligência que determinam diferentes níveis de complexidade, conforme relata Beluzzo (2005) e Dudziak (2002):

a) Ênfase na tecnologia da informação - Digital: Abordagem do ponto de vista dos sistemas. Desenvolve habilidades no uso de ferramentas e suportes tecnológicos 
limitando ao simples aprendizado de habilidades e conhecimentos instrumentais. Praticamente mecânicos, tem como foco o acesso à informação;

b) Ênfase nos processos cognitivos - Informação propriamente dita: Relaciona ao processo de busca da informação para construção de conhecimento. Os sistemas de informação são examinados à maneira como são percebidos pelo indivíduo procurando entender como as pessoas buscam sentido para seus questionamentos e pesquisas, a partir de suas habilidades e conhecimentos envolvendo uso, interpretação e busca de significados;

c) Ênfase no aprendizado ao longo da vida - inteligência: Engloba além de uma série de habilidades e conhecimentos, a noção de valores ligados à dimensão social e situacional.

Belluzo (2005) acredita na necessidade de interlocução das três ênfases para dimensioná-la sobre o domínio de saberes e habilidades, de natureza vária que permita a intervenção prática na realidade, além do estabelecimento de uma visão crítica do alcance das ações e o compromisso com as necessidades mais concretas que emergem e caracterizam o atual contexto social.

A competência informacional estabelece que o indivíduo possa aprender a aprender buscar, avaliar, usar e criar a informação de forma efetiva para atingir suas metas pessoais, sociais, ocupacionais e educacionais.

Conforme INFLANET (2005) a competência informacional é um direito humano básico em um mundo digital sendo o guia da Sociedade da Informação para o desenvolvimento, a prosperidade e a liberdade, promovendo assim a inclusão social, isto porque, através do desenvolvimento de competência, é possível enfrentar os desafios tecnológicos, econômicos e sociais, para reverter a desvantagem e incrementar o bem estar de todos.

Dudziak (2003) assim se expressa sobre competência informacional:

Para ser competente em informação, uma pessoa deve ser capaz de reconhecer quando uma informação é necessária e deve ter a habilidade de localizar, avaliar e usar efetivamente a informação. Resumindo, as pessoas competentes em informação são aquelas que aprenderam a aprender. Elas sabem como aprender, pois sabem como o conhecimento é organizado, como encontrar a informação e como usá-la de modo que outras pessoas aprendam a partir dela (DUDZIAK, 2003, p.26).

A formação de competência informacional pode ser definida como um: Conjunto de conhecimentos, habilidades e atitudes correlacionados que afeta parte considerável da atividade de alguém, se relaciona com o desempenho, pode ser medido segundo padrões preestabelecidos e pode ser melhorado por meio de treinamento e desenvolvimento (MIRANDA, 2004, p.115)

Existem algumas palavras-chave no que Zarifian (2003 apud MIRANDA, 2004) considera uma definição multidimensional da competência:

1. iniciativa;

2. responsabilidade;

3. inteligência;

4. prática;

5. conhecimentos adquiridos;

6. transformação;

7. diversidade;

8. mobilização dos atores, e;

9. compartilhamento. 
Essas palavras-chave dizem respeito à principal virtude da lógica da competência centrando atenção sobre o indivíduo e suas qualidades (MIRANDA, 2004).

Bruce (1997 apud AUN E MOURA, 2007) apresenta um modelo de entendimento de competência informacional, denominado modelo relacional, enfatizando determinadas concepções e experiências. Para o autor, a competência informacional se inicia por uma questão situacional experimentada pelos sujeitos. Ele denominou sete faces da competência informacional:

1. Tecnologia da informação: habilidade de utilização da tecnologia para a recuperação da informação e comunicação;

2. Fontes de informação: habilidade de recuperar a informação, conhecendo as fontes de informação e sua estrutura; utilizando-a independentemente, com flexibilidade ou através de um intermediário.

3. Processo de informação: habilidade de confrontar problemas e saber encontrar e usar a informação necessária para resolvê-los.

4. Controle de informação: habilidade de manter a informação organizada de forma que assegure a recuperação fácil e a possibilidade de manipula-la quando necessário. Os recursos utilizados podem ser armários de arquivamento; cérebro ou a memória através dos vários formulários das ligações e das associações.

5. Construção de conhecimento: habilidade de entender a informação desenvolvendo uma base pessoal de conhecimento em temas que não se conhecia anteriormente. Envolve o uso de estratégias que, combinada com reflexão e pensamento critico, permite a adoção de perspectivas pessoais.

6. Extensão do conhecimento: habilidade de entender a capacidade de trabalhar com conhecimentos e perspectivas pessoais para obter novos conhecimento e pontos de vista. Usa-se a informação de forma criativa.

7. Extensão da sabedoria: a competência informacional envolve como usar a informação com sabedoria e inteligência para beneficio próprio além da produção de nova informação, incluindo a utilização da própria experiência, de acordo com atitudes, crenças e valores pessoais.

A sociedade contemporânea caracteriza e atribui a construção do conhecimento essencial para ascensão econômica e social, no entanto, deve-se apontar que esse conhecimento existe somente no ser humano e somente pode ser mobilizado pelas pessoas. 0 mesmo acontece com a competência.

O uso da Tecnologia da Informação agiliza a transmissão da informação e a facilita o seu respectivo acesso em tempo quase simultâneo, permitindo troca de ideias sobre os mais variados assuntos. Porém:

Não se deve esquecer que as TIC's não permitem a produção do conhecimento, em si. O conhecimento surge de perguntas sobre as mais variadas situações, o que exige tempo de reflexão por parte do sujeito. Conhecimento é produzido a partir de análises, de interpretações de dados, o que pressupõe, também, a reflexão (BARRETO, 2005, p 171).

A competência é a iniciativa sob a condição de autonomia, que supõe a mobilização de dois tipos de recursos: os recursos internos pessoais (adquiridos, solicitados e desenvolvidos pelos indivíduos em dada situação) e os coletivos (soma das competências individuais). É a faculdade de mobilizar redes de atores em volta das mesmas situações, de compartilhar desafios, de assumir áreas de responsabilidade (MIRANDA, 2004). 


\section{CONSIDERAÇÕES FINAIS}

As redes sociais virtuais são uma ferramenta com possibilidades múltiplas para usuários e empresas que possui aspectos positivos e negativos. Descartá-las ou deixar de dar a elas a devida atenção, seria não aceitar que vivemos em plena era da Informação e Conhecimento.

Cabe aos consumidores ter senso crítico na utilização da ferramenta. Para os consumidores e usuários sem fins lucrativos, a melhor maneira de aproveitar todas as vantagens, é dar a devida dimensão a eles em suas vidas. A amplitude da intensidade de utilização dessas ferramentas é muito grande. Cada um define seu ponto de equilíbrio entre ser usuário ou escravo do sistema. Em suma, os usuários devem saber dosar o nível de "seriedade" que as dão.

Conclui-se que por meio das redes sociais, certamente o usuário não será capaz de dominar o universo informacional tornando-se autônomo para designar habilidades ligadas ao uso da informação e criando soluções para seus problemas e se denominar competente informacional. No entanto, pode se apresentar como uma porta de entrada para interagir com a tecnologia e procurar novas fontes de informação, rumo à aquisição de novos conhecimentos.

O mundo "business", por sua vez (empresas e marcas), caminha para encarála de forma cada vez mais séria e profissional. É aí que está a comunicação da nova "era do conhecimento": será no mundo virtual que os consumidores e marcas dialogarão.

Pode pontuar as seguintes características sobre a competência informacional:

1. Ferramenta auto motivante que apresenta informação de forma criativa, amplia as possibilidades de interação, potencializa o acesso à informação e identifica problemas e motiva a busca de soluções;

2. Fonte de comunicação alternativa, isto é, fonte de informação aberta que possibilita a expressão de opiniões livremente, desvinculando dos meios formais de comunicação. Com possibilidade de compartilhar informação com outros usuários e confrontar problemas de diversos contextos.

3. Possibilita a construção de identidade por meio do desenvolvimento da autoimagem com construção da página pessoal - uma atitude pró-ativa que admite a elaboração do perfil pessoal e a formação de comunidades (grupos) avaliando criticamente seu conteúdo segundo critérios de relevância, pertinência, lógica, ética e incorporando as informações selecionadas ao seu próprio grupo de comunidade, que geralmente comprova sua trajetória de vida, gosto, estilo, atitudes.

4. Permite o entretenimento.

Esses fatores são importantes vias para o usuário se engajar em projetos e problemas, buscando respostas e levantando novas questões à medida que interage, não formando uma atitude passiva diante da realidade (FIALHO; MOURA, 2005).

No entanto, deve-se atentar para alguns problemas do conteúdo informacional:

1. Não constitui uma fonte de informação cientifica / confiável, sendo permeada de opiniões pessoais e sem fundamento teórico;

2. Não distingue fato, ponto de vista e opinião;

3. Não distingue informação inexata e capciosa.

\section{REFERÊNCIAS}

AGUIAR, Sonia. Redes sociais e tecnologias digitais de informação e

comunicação: relatório final de pesquisa. Rio de Janeiro: Nupef/RITs, 2006. 
Disponível em: http://www.nupef.org.br/downloads/rel nupef redes 2006.pdf. Acesso em: 21 jun. 2007.

AUN, Marta Pinheiro; MOURA, Maria Aparecida. A construção de indicadores nacionais de acesso público aos meios digitais: princípios e perspectivas. In: AUN, Marta Pinheiro (org.) Observatório da Inclusão digital: descrição e avaliação dos indicadores adotados nos programas governamentais de infoinclusão. Belo Horizonte: Gráfica Orion, 2007. cap. 1.

BARRETO, Angela Maria. O fator humano e o desenvolvimento de competências nas unidades de informação. Perspectiva em Ciência Informação, Belo Horizonte, v.10, n.2, p.194-207. jul;dez. 2005.

BELLUZZO, Regina Célia Baptista. A competência em informação: um fator de integração entre a biblioteca e a escola. In: Congresso Brasileiro de Biblioteconomia, Documentação e Ciência da Informação CBBD, 21, Curitiba, 2005. Anais. Curitiba: CBBD, 2005. CDROM.

BRAMAN, Sandra. Information Technology, National Identity, \& Social Cohesion - A Report of The Project on Technology Futures and Global Power, Wealth, and Conflict. Washington: The CSIS Press, 2005.

BRUCE, Christine. The seven faces of information literacy. Adelaide: Auslib Press, 1997. Disponível em: http://sky.fit.qut.edu.au/ bruce/inflit/faces/faces1.php. Acesso em: 13 mai. 2007.

CAPRA, Fritjot. Redes sociais. Wikipedia. Disponível em: http://pt.wikipedia.org/wiki/Redes sociais. Acesso em: 01 mai. 2007.

CASTELLS, Manuel. Outro mundo: a era da intercomunicação. Le Monde Diplomatique. Ago. 2006. Disponível em: http://diplo.uol.com.br/2006-08,a1379. Acesso em: 22 mai. 2007.

DRUCKER, F. Peter. Sociedade Pós-Capitalista. 3 ed. São Paulo: Pioneira, 1993.

DUDZIAK, Elisabeth Adriana. Information literacy: princípios, filosofia e prática. Ciência da Informação, Brasília, v. 32, n. 1, p. 23-35, jan./abr. 2003.

DUDZIAK, Elisabeth Adriana. Information Literacy: uma revolução silenciosa, diferentes concepções para a competência em informação. 2002.

FERREIRA, Sueli Mara Soares Pinto. A biblioteca digital com foco no desenvolvimento das competências informacional e científica na comunidade. In: SIMPÓSIO INTERNACIONAL DE BIBLIOTECAS DIGITAIS, 3., 2005, São Paulo. Disponível em: http://hdl.handle.net/1904/19299. Acesso em: 16 mai. 2007.

FIALHO, Janaina Ferreira; MOURA, Maria Aparecida. A formação do pesquisador juvenil. Perspectiva em Ciência Informação, Belo Horizonte, v.10, n.2, p.194-207. jul;dez. 2005.

INFLANET International Federation of Library Associations and Institutions. Faróis da sociedade da informação: declaração de Alexandria sobre a competência informacional e aprendizado ao longo da vida. Alexandria: IFLA: UNESCO, 2008 
Disponível em: http://www.ifla.org/III/wsis/BeaconInfSsoc-pt.html. Acesso em: 19 fev. 2016.

LASTRES, Helena M.M.; CASSIOLATO, José E; ARROIO, Ana. Conhecimento, sistema de inovação e desenvolvimento. Rio de Janeiro: UFRJ; Contraponto, 2005.

MIRANDA, Silvânia Vieira. Identificando competências informacionais. Ciência da Informação, Brasília, v.33, n.2, p.112-122, mai/ago. 2004.

SERRES, Michel. A comunicação contra a cultura: entre a Disneylândia e os ayatolás. Alceu 8. v.4, n.8, jan./jun, 2004. Disponível em: http://publique.rdc.pucrio.br/revistaalceu/cgi/cgilua.exe/sys/start.htm?infoid=87\&sid=17\&tpl=printervie was. Acesso em: 03 jun. 2007.

SILVA, Lídia Loureiro da. Globalização das Redes de Comunicação: uma reflexão sobre as implicações cognitivas e sociais. Biblioteca online de ciência da comunicação. 1999. Disponível em:

http://www.bocc.ubi.pt/ esp/autor.php?codautor=63. Acesso em: 29 mai. 2007.

ZARIFIAN, Philippe. 0 modelo da competência: trajetória histórica, desafios atuais e propostas. São Paulo: Senac, 2003. 192 p.

Editores do artigo: Adilson Luiz Pinto e Rafaela Paula Schmitz 